\title{
Biosynthesis of dendroketose
} from different carbon sources using in vitro and in vivo metabolic engineering strategies

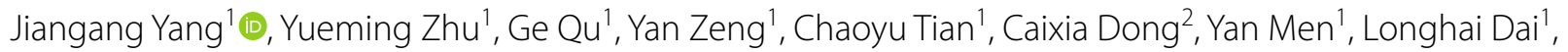
Zhoutong Sun ${ }^{1 *}$, Yuanxia Sun ${ }^{1 *}$ and Yanhe Ma ${ }^{1}$

\begin{abstract}
Background: Asymmetric aldol-type C-C bond formation with ketones used as electrophilic receptor remains a challenging reaction for aldolases as biocatalysts. To date, only one kind of dihydroxyacetone phosphate (DHAP)dependent aldolases has been discovered and applied to synthesize branched-chain sugars directly using DHAP and dihydroxyacetone (DHA) as substrate. However, the unstable and high-cost properties of DHAP limit large-scale application. Therefore, biosynthesis of branched-chain sugar from low-cost and abundant carbon sources is essential.

Results: The detailed catalytic property of L-rhamnulose-1-phosphate aldolase (RhaD) and L-fuculose-1-phosphate aldolase (FucA) from Escherichia coli in catalyzing the aldol reactions with DHA as electrophilic receptors was characterized. Furthermore, we calculated the Bürgi-Dunitz trajectory using molecular dynamics simulations, thereby revealing the original sources of the catalytic efficiency of RhaD and FucA. A multi-enzyme reaction system composed of formolase, DHA kinase, RhaD, fructose-1-phosphatase, and polyphosphate kinase was constructed to in vitro produce dendroketose, a branched-chain sugar, from one-carbon formaldehyde. The conversion rate reached $86 \%$ through employing a one-pot, two-stage reaction process. Moreover, we constructed two artificial pathways in Corynebacterium glutamicum to obtain this product in vivo starting from glucose or glycerol. Fermentation with glycerol as feedstock produced $6.4 \mathrm{~g} / \mathrm{L}$ dendroketose with a yield of $0.45 \mathrm{~mol} / \mathrm{mol}$ glycerol, representing $90 \%$ of the maximum theoretical value. Additionally, the dendroketose production reached $36.3 \mathrm{~g} / \mathrm{L}$ with a yield of $0.46 \mathrm{~mol} / \mathrm{mol}$ glucose when glucose served as the sole carbon resource.

Conclusions: The detailed enzyme kinetics data of the two DHAP-dependent aldolases with DHA as electrophilic receptors were presented in this study. In addition, insights into this catalytic property were given via in silico simulations. Moreover, the cost-effective synthesis of dendroketose starting from one-, three-, and six-carbon resources was achieved through in vivo and in vitro metabolic engineering strategies. This rare branched-chain ketohexose may serve as precursor to prepare 4-hydroxymethylfurfural and branched-chain alkanes using chemical method.
\end{abstract}

Keywords: Aldol reactions, Aldolase, Branched-chain sugar, Formaldehyde, Metabolic engineering

\footnotetext{
*Correspondence: sunzht@tib.cas.cn; sun_yx@tib.cas.cn

${ }^{1}$ National Engineering Laboratory for Industrial Enzymes, Tianjin Institute of Industrial Biotechnology, Chinese Academy of Sciences, Tianjin 300308,

China

Full list of author information is available at the end of the article
} 


\section{Background}

Directed aldol reaction is one of the most powerful carbon-carbon bond-forming procedures in synthetic organic chemistry and enables the concomitant creation of functionalized stereogenic centers and construction of chiral complex polyhydroxylated molecules $[1,2]$. Catalytic asymmetric addition of carbon nucleophiles (donor) to ketones (acceptor) is a fundamental approach to construct new tetrasubstituted stereogenic carbon centers. This reaction is synthetically efficient to synthesize chiral tertiary alcohols, which are important building blocks of naturally occurring and artificial biologically active molecules [3]. Aldol addition with ketones as electrophilic receptors is extremely challenging compared with the catalytic enantioselective aldol reaction to aldehydes. Few successful examples have been shown in catalytic aldol reaction to ketones, and they rely on metal catalysts or highly reactive trichlorosilyl enolate of methyl acetate [4-6]. However, all these reactions have a narrow substrate scope and depend on activated ketone acceptors or chiral auxiliaries.

Biocatalyzed aldol additions are attractive because this type of reaction occurs under mild conditions. As such, aldolases are particularly compatible as catalysts in the production of chiral compounds due to high selectivity and catalytic efficiency [7, 8]. A number of aldolases for catalyzing enantioselective aldol additions taking aldehydes as acceptors have been developed [9]. However, to date, only two aldolases that can use ketones as acceptors have been reported. One is pyruvate-dependent aldolase from Pseudomonas taetrolens, which exhibits the catalytic ability in aldol addition of pyruvate to a ketone acceptor indole-pyruvic acid and has been used in the stereoselective synthesis of a precursor of monatin [10, 11]. The other one is L-rhamnulose-1-phosphate aldolase (RhaD) from Bacteroides thetaiotaomicron. This enzyme catalyzes the aldol reaction between DHAP and several ketones (hydroxyacetone, 1-hydroxybutanone, hydroxypyruvate and L-erythrulose) and gave four branched-chain sugars by coupling an acid phosphatase [12]. The development of several kinds of aldolases that can tolerate ketones as electrophilic receptors is necessary in the asymmetric catalysis field.

Branched-chain sugars, e.g., dendroketose, which belong to a class of rare sugars, are monosaccharides, which rarely exist in nature [13]. Dendroketose was obtained from the polymerization of two molecules of dihydroxyacetone [14, 15]. Typically, dendroketose that contains a tertiary alcohol moiety can be chemically dehydrated to furfural derivatives 4-hydroxymethylfurfural (4-HMF) which showed broad application prospects in preparing fine chemicals [16]. Such conversion is similar to that of fructose to 5-hydroxymethylfurfural
(5-HMF) [17]. The synthesis of 2,5-dimethylfuran (DMF) from 5 -HMF is a highly attractive route to a renewable fuel [18]. The feasibility of producing 2,4-dimethylfuran (2,4-DMF) or $\mathrm{C}_{9}-\mathrm{C}_{15}$ branched-chain alkanes as liquid transportation fuels from 4-HMF has also been demonstrated [19]. Therefore, developing methods that can synthesize branched-chain sugar is meaningful. The asymmetric aldol addition reactions via DHAP-dependent aldolases are particularly striking strategies in preparation of innovative branched-chain sugars due to the direct and rapid creation of molecular complexity in benign environments [7]. DHAP-dependent aldolases exhibit a strict specificity for the donor DHAP [20]. However, compound DHAP is unstable [21] and currently very expensive. These conditions limit their large-scale application.

In this work, we investigated the catalytic properties of two DHAP-dependent aldolases with ketones as electrophilic receptors. Moreover, we calculated the Bürgi-Dunitz trajectory using molecular dynamics (MD) simulations to reveal the original sources of the catalytic efficiency. Finally, an in vitro multi-enzyme system was designed, and two in vivo artificial pathways were constructed in Corynebacterium glutamicum to synthesize dendroketose from one-, three-, and six-carbon resources.

\section{Results and discussion}

\section{Aldol reactions to DHA catalyzed by DHAP-dependent aldolases}

DHAP-dependent aldolases have been widely investigated for the synthesis of several new deoxy or phosphorylated sugars and iminocyclitols [22-24]. Naturally, this class of enzyme utilizes DHAP as the donor substrate and accepts a broad range of acceptor aldehydes. Well-known members of this class include FucA, RhaD, fructose 1,6-diphosphate aldolase (FruA), and tagatose 1,6-diphosphate aldolase (TagA). To date, only one kind of DHAP-dependent aldolases has been discovered in catalyzing the aldol reaction between DHAP and ketones and in synthesizing branched-chain sugars [12]. To investigate whether other kinds of DHAP-dependent aldolases showed this catalytic property, RhaD, FucA, TagA and FruA from Escherichia coli were used as candidates to catalyze the aldol reaction between DHAP and DHA. Expectedly, both FucA and RhaD enabled the direct aldol addition of DHAP to DHA to form a new compound in combination of acid phosphatase (AP) with conversions of $17 \%$ and $73 \%$, respectively (Fig. 1 and Table 1 ). The RhaD also accepted DHA as nucleophile donor [25]. Therefore, we carried out the aldol reaction with DHA as the sole substrate. An identical product was obtained with a low conversion (7\%); however, the reaction needed 


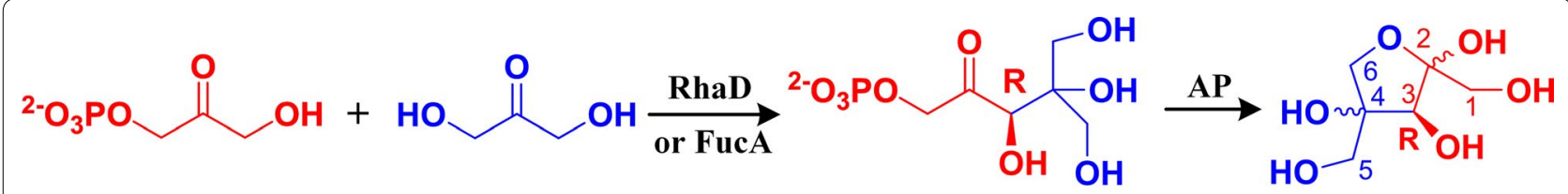

DHAP

DHA

Dendroketose-1-phosphate

Dendroketose

Fig. 1 DHAP/DHA-dependent aldolases catalyze the aldol reaction between DHAP and DHA. RhaD L-rhamnulose-1-phosphate aldolase, FucA L-fuculose-1-phosphate aldolase, AP acid phosphatase

Table 1 Steady-state kinetic parameters of aldol reactions to DHA catalyzed by RhaD and FucA

\begin{tabular}{lllllcccc}
\hline & Product & Donor & Acceptor & Conversion (\%) & $\boldsymbol{V}_{\mathbf{m a x}}(\mathbf{U} / \mathbf{m g})$ & $\boldsymbol{K}_{\mathbf{M}}(\mathbf{m M})$ & $\boldsymbol{k}_{\text {cat }}\left(\mathbf{s}^{\mathbf{- 1}}\right)$ & $\begin{array}{c}\mathbf{1 0}^{\mathbf{3}} \times \boldsymbol{k}_{\text {cat }} / \boldsymbol{K}_{\mathbf{M}} \\
\left(\mathbf{s}^{-\mathbf{1}} \mathbf{m M}^{-\mathbf{1}}\right)\end{array}$ \\
\hline RhaD & L-Fructose & DHAP & L-GAL & $92^{\mathrm{a}}$ & $4.3 \pm 0.5$ & $40.8 \pm 5.8$ & $20.5 \pm 2.5$ & $500 \pm 64$ \\
& Dendroketose & DHAP & DHA & 73 & $0.86 \pm 0.24$ & $23.4 \pm 9.69$ & $4.1 \pm 0.52$ & $180 \pm 40$ \\
\multirow{2}{*}{ FuCA } & L-Tagatose & DHAP & L-GAL & NT & $1.5 \pm 0.3$ & $54.1 \pm 3.6$ & $5.0 \pm 0.53$ & $92 \pm 13$ \\
& Dendroketose & DHAP & DHA & 17 & $0.32 \pm 0.13$ & $309.8 \pm 45.2$ & $0.45 \pm 0.13$ & $1.4 \pm 0.5$ \\
\hline
\end{tabular}

NT not test

a This result has been shown in previous paper [38]

longer reaction time of $96 \mathrm{~h}$. Naturally, DHAP-dependent aldolases create two new stereogenic centers at $\mathrm{C}$-atoms 3 and 4 [22]. In our work, nuclear magnetic resonance (NMR) analysis showed that both the products obtained from RhaD and FucA have two hydroxymethyl groups at C-4 carbon presenting a branched-chain sugar. RhaD and FucA from E. coli have been crystallized and showed a strict 3R-stereoselectivity due to mechanistic requirements $[26,27]$. Therefore, those two enzymes shared identical product termed as dendroketose and can be obtained by self-aldolization of DHA using chemical method [19]. Enzymes TagA and FruA from E. coli failed to catalyze aldol addition to DHA. Given that RhaD and FucA are class II aldolases, we further measured the catalytic aldol addition to DHA using the class I aldolase, such as fructose 6-phosphate aldolase (FSA) and FruA from rabbit muscle (RAMA). No product was detected when using RAMA and FSA.

\section{Molecular dynamic simulations provide insights into the catalytic properties of RhaD and FucA}

To gain insights into the catalytic properties of RhaD and FucA from E. coli, we determined the apparent steady-state kinetic parameters in the reactions of the nucleophile DHAP and acceptor DHA. Substrate L-glyceraldehyde ( $\mathrm{L}$-GAL) was evaluated as the control to compare the catalytic properties when using aldehyde and ketone as acceptors. Despite the lower $K_{\mathrm{M}}$ value of RhaD to DHA (23.4 mM) than that of L-GAL ( $40.8 \mathrm{mM})$, the $k_{\text {cat }} / K_{\mathrm{M}}$ value of RhaD to DHA was threefold lower than that of L-GAL (Table 1). These results indicated that
DHA binds to RhaD with higher affinity but with lower catalytic activity than L-GAL. In the case of FucA, the $k_{\text {cat }} / K_{\mathrm{M}}$ value of FucA to DHA was 65 -fold lower than that of FucA to L-GAL. This result indicated that the catalytic activity of FucA toward DHA was significantly lower than that to L-GAL. In terms of $k_{\text {cat }} / K_{\mathrm{M}}$, clearly, the value of RhaD to DHA was 350-fold higher than that of FucA to DHA. This finding suggested that RhaD is much more efficient in catalyzing the aldol reaction between DHAP and DHA than FucA. According to the $K_{\mathrm{M}}$ value of FucA in Table 1, the failure of FruA and TagA in catalyzing the aldol addition to DHA was probably due to very low affinity and catalytic efficiency to this substrate.

Four dimer models of enzyme-substrate complexes (dubbed as "FucA-DHAP-DHA", "FucA-DHAP-GAL", "RhaD-DHAP-DHA" and "RhaD-DHAP-GAL") (Fig. 2) were correspondingly subjected to $\mathrm{MD}$ simulations at $300 \mathrm{~K}$ (to mimic the experimental conditions) for $100 \mathrm{~ns}$ to clarify the possible reasons of the distinct kinetic parameters of FucA and RhaD at the molecular level. Root-mean-square deviation (RMSD) along with rootmean-square fluctuation (RMSF) analysis suggested that the simulated trajectories of all four systems were stable and realizable (Additional file 1: Figures S1 and S2). In organic chemistry theory, the Bürgi-Dunitz angle $\left(\alpha_{\mathrm{BD}}\right)$ describes the trajectory of approach of a nucleophile to an electrophile (Fig. 3a). In addition, the value of $\alpha_{\mathrm{BD}}$ determines whether enzymatic reactions form reactive Michaelis complexes or are arrested. The $\alpha_{\mathrm{BD}}$ analysis is proved to be a very helpful method in evaluating whether enzymatic reactions are active or not $[28,29]$. The ideal 


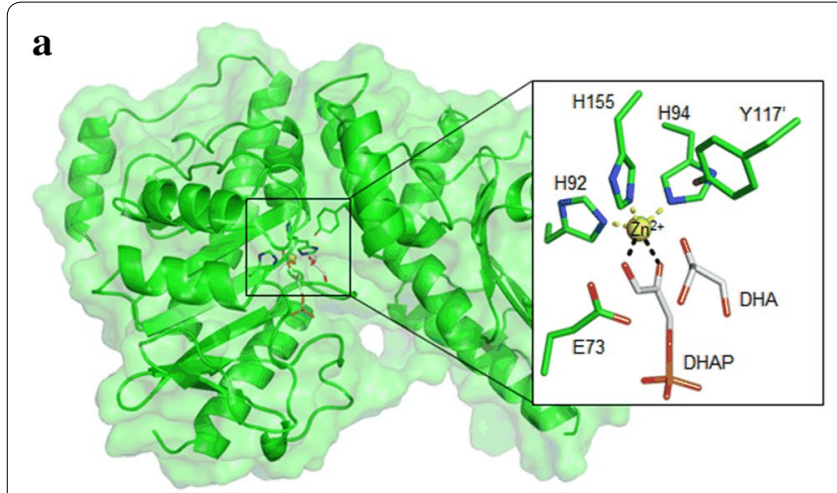

c

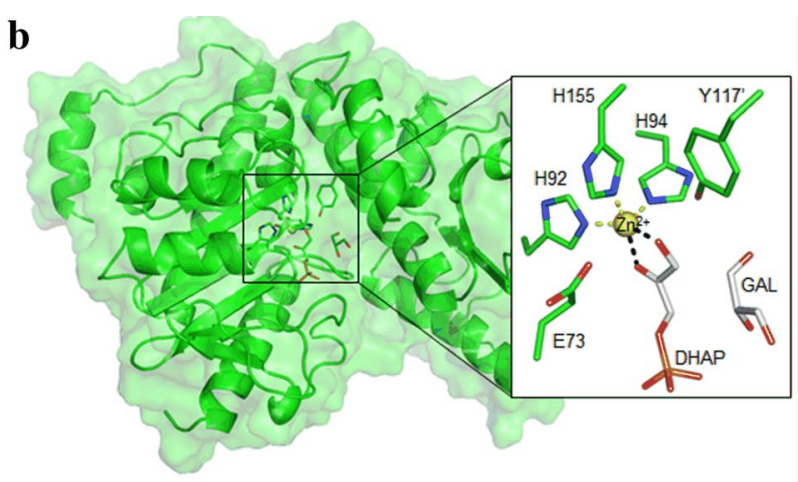

d
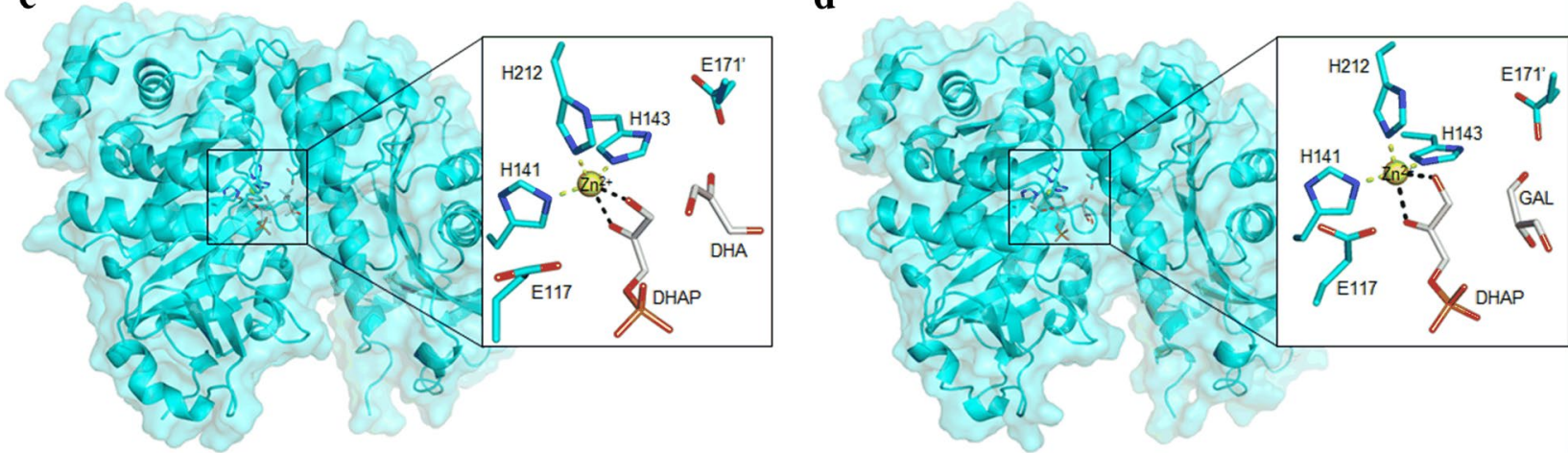

Fig. 2 Overview of FucA complex and RhaD complex. a FucA-DHAP-DHA; b FucA-DHAP-GAL; c RhaD-DHAP-DHA; d RhaD-DHAP-GAL. Yellow sphere represents zinc ion; white sticks show substrates; green and cyan sticks depict the key residues in FucA and RhaD, respectively

$\alpha_{\mathrm{BD}}$ observed in enzymatic reactions involving the carbonyl groups (e.g., in transaldolase [30], protease [31], and alcohol dehydrogenase [32]) may well differ from the value determined and calculated in organic chemistry $\left(>105 \pm 5^{\circ}\right)$ but will certainly be $>90^{\circ}$. In our study, we analyzed the calculated $\alpha_{\mathrm{BD}}$ values between the nucleophile DHAP C-atom $\left(\mathrm{C}_{\mathrm{nu}}\right)$ and the electrophile $s p 2$ carbonyl $\left(\mathrm{C}_{\mathrm{el}}-\mathrm{O}\right)$ in all four systems (FucA-DHAP-DHA, FucA-DHAP-GAL, RhaD-DHAP-DHA, and RhaDDHAP-GAL). The catalytic efficiency of FucA and RhaD is dependent on how often the nucleophile and electrophile are present in properly positioned poses and can be reflected at calculated $\alpha_{\mathrm{BD}}$ value. The average $\bar{\alpha}_{\mathrm{BD}}$ value $\left(90.85^{\circ}\right)$ in FucA-DHAP-DHA system was lower than that of L-GAL as acceptor for FucA $\left(\bar{\alpha}_{\mathrm{BD}}=103.25^{\circ}\right)$ (Fig. 3b, c). Moreover, the $\bar{\alpha}_{\mathrm{BD}}$ value $\left(97.43^{\circ}\right)$ in RhaDDHAP-DHA was higher than that $\left(90.85^{\circ}\right)$ of FucADHAP-DHA but lower than RhaD-DHAP-L-GAL (Fig. 3d, e). These in silico results were supported by the $k_{\text {cat }}$ value.

\section{Construction of in vitro multi-enzyme system to produce dendroketose from formaldehyde}

One-carbon compounds as a low-cost, abundant feedstock option have been recently drawing attention in energy and chemical fields [33]. The bioconversion of one-carbon compounds into high-value products is under investigation [34,35]. Here, we attempted to construct a multi-enzyme system to in vitro synthesize dendroketose with formaldehyde (FALD) as substrate. This system comprised five enzymes, such as formolase (FLS), DHA kinase (DhaK), RhaD, fructose-1-phosphatase (YqaB), and polyphosphate kinase (PPK) (Fig. 4). The enzyme FLS was a computationally designed enzyme with benzaldehyde lyase from Pseudomonas fluorescens as starting point. FLS catalyzes the continuous carboligation of FALD to DHA with thiamine pyrophosphate (TPP) as cofactor [36]. DHA phosphorylation catalyzed by DhaK with adenosine triphosphate (ATP) as cofactor contributes in obtaining DHAP. To recycle using ATP, an ATP regeneration system based on PPK and polyphosphate was introduced into the reaction system. Enzyme RhaD catalyzed the aldol addition of the resulting DHAP to DHA to give dendroketose-1-phosphate. The latter was then dephosphorylated by YqaB to synthesize dendroketose (Fig. 4). Along this line, the FLS, DhaK from Citrobacter freundii [37], RhaD, YqaB from E. coli [38], and PPK from Rhodobacter sphaeroides [39] were chosen to construct this multi-enzyme reaction system. Those five enzymes were individually expressed in $E$. 

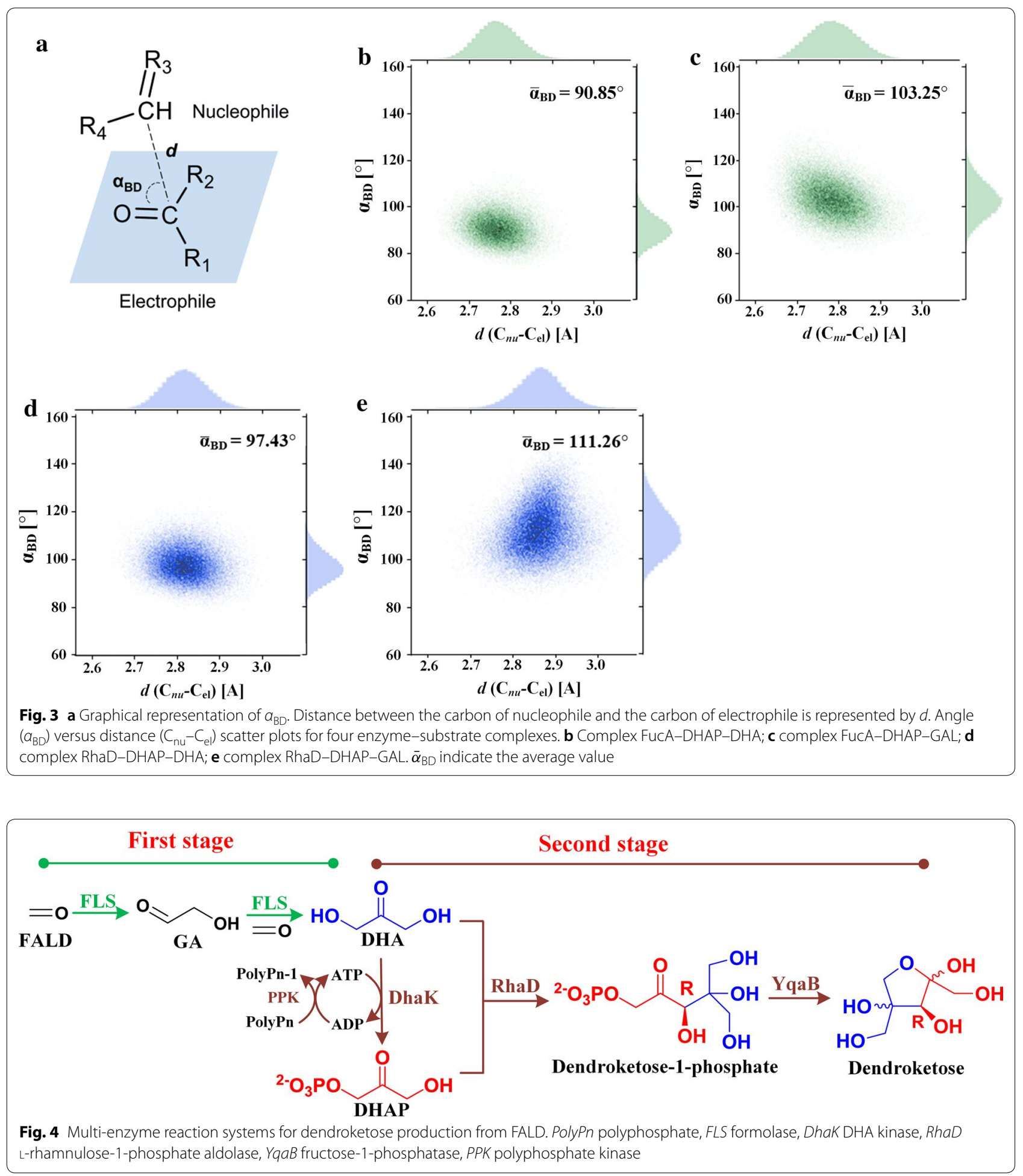

coli BL21(DE3). The key information including the Uniprot/Genebank number and enzyme activity for those enzymes is summarized in Table 2 . The specific activities of purified enzymes for FLS, RhaD and PPK were 0.09, 0.27 and $18.2 \mathrm{U} / \mathrm{mg}$, respectively.

In our multi-enzyme system, the conversion of FALD to DHA was the key step. When FLS catalyzes this 
Table 2 The key information of enzymes used in multi-enzyme system

\begin{tabular}{lllll}
\hline Enzyme & Resource & Uniprot/genebank & $\begin{array}{l}\text { Specific activities } \\
\text { (U/mg) }\end{array}$ & References \\
\hline L-Rhamnulose-1-phosphate aldolase (RhaD) & Escherichia coli & P32169 & 0.27 & This study \\
Fructose-1-phosphatase (YqaB) & Escherichia coli & P77475 & 0.6 & {$[38]$} \\
Formolase (FLS) & Pseudomonas fluorescens & P51853 & 0.09 & This study \\
DHA kinase (DhaK) & Citrobacterfreundii & P45510 & 22 & [37] \\
Polyphosphate kinase (PPK) & Rhodobacter sphaeroides & AWD23073.1 & 18.2 & This study \\
\hline
\end{tabular}

a The enzyme FLS was a mutant of benzaldehyde lyase (BAL) (Uniprot P51853) at A28I, A394G, G419N, and A480W substitution

carboligation reaction, a small amount of intermediate product glycolaldehyde (GA) was produced [36]. The aldolase RhaD not only converts DHAP and DHA to dendroketose but also catalyzes the aldol addition to substrate FALD and intermediate GA to D-erythrulose and L-xylulose, respectively [40]. We initially mixed the purified enzymes of FLS, DhaK, RhaD, YqaB, and PPK into one-pot reaction medium. However, a mixture of L-xylulose (68\%), D-erythrulose (11\%) and dendroketose (31\%) was obtained (data no shown). In our previous study, onepot, two-stage reaction process was used to decrease the byproduct formation and increase the product yield during the multi-enzyme cascade reaction with FALD as the sole substrate [34]. Here, this one-pot, two-stage reaction process was again employed. In the first stage, the high conversion of FALD to DHA catalyzed by FLS should be achieved. In the second stage, four other enzymes converted the resulting DHA to dendroketose (Fig. 4). Accordingly, we mixed FLS (1.5 U, $16 \mathrm{mg}$ ) and $0.1 \mathrm{mM}$ TPP at different concentration of FALD $(20,40,60$, 80, $100,200 \mathrm{mM}$ ) in the reaction medium and performed the reaction at $30{ }^{\circ} \mathrm{C}$ for $16 \mathrm{~h}$ in the first stage. The conversion rate of DHA maintained high level (>90\%) at FALD concentration of 20 or $40 \mathrm{mM}$. However, this rate decreased when FALD concentration was equal to or higher than $60 \mathrm{mM}$, and no conversion was observed at $200 \mathrm{mM}$ FALD (Fig. 5a). We further measured the enzyme activity of FLS under different FALD concentration. The catalytic ability of FLS indeed decreased when FALD concentration is higher than $60 \mathrm{mM}$ and was absolutely inactivated at $200 \mathrm{mM}$. Those results indicated that higher FALD concentration inhibited the enzyme activity of FLS and decreased the formation of DHA.

When $40 \mathrm{mM}$ FALD was used, the system produced $12.1 \mathrm{mM}$ DHA with a conversion rate of $91 \%$. This value was calculated with the ratio of DHA formation amount to initial concentration of FLAD. The GA has not been detected in this system. This result was identical to the previous study for which DHA was the primary product at high concentrations of FALD $(>10 \mathrm{mM})$ [41]. In the second stage, the individually purified enzymes DhaK, RhaD, YqaB, PPK, $10 \mathrm{mM}$ polyphosphate, $0.5 \mathrm{mM}$ ATP
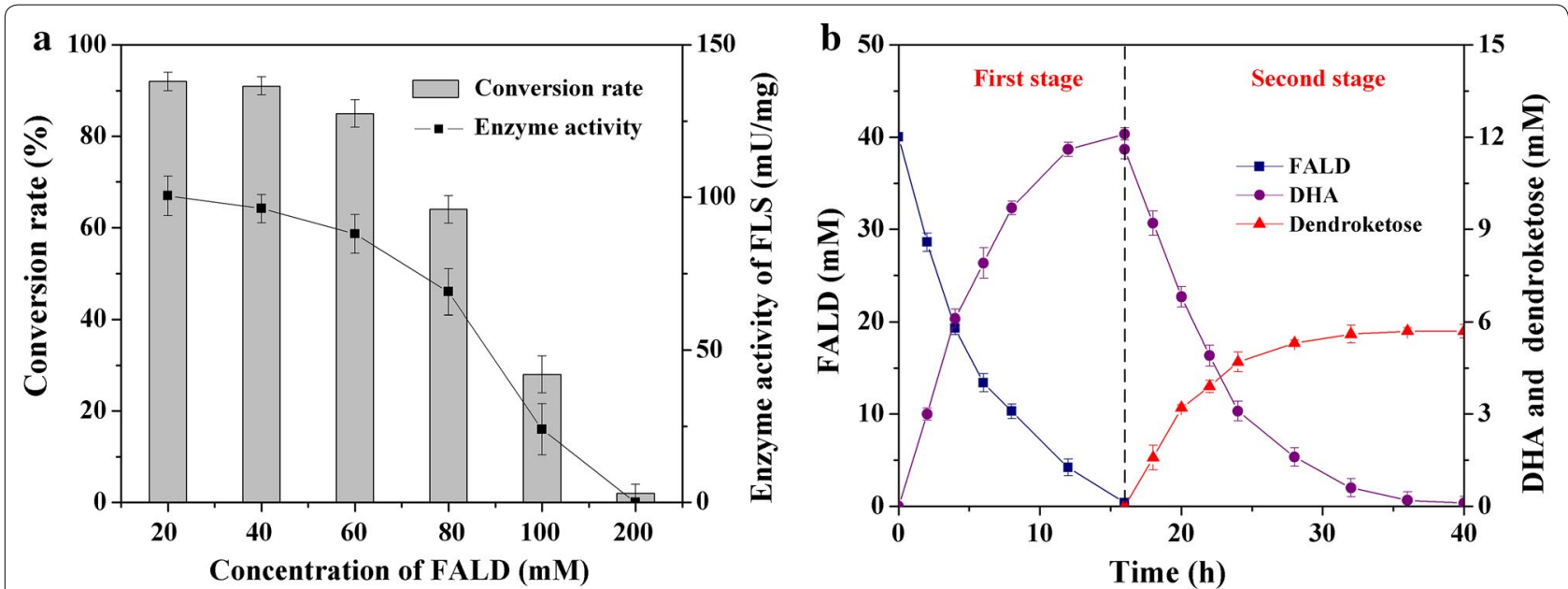

Fig. 5 a The influence of FALD concentration on FALD conversion and FLS enzyme activity. The conversion rate was calculated with the ratio of DHA formation amount to initial concentration of FLAD. One unit of enzyme activity was defined as the enzyme amount catalyzing the formation of $1 \mu \mathrm{mol}$ of total DHA and GA per min. b Time course of one-pot, two-stage cascade reaction process to synthesize dendroketose from FALD; mean and error bars were calculated based on triplicate experiments 
and $5 \mathrm{mM} \mathrm{MgSO} 4$ were added into the reaction system. After reaction for another $24 \mathrm{~h}$, this system produced $5.7 \mathrm{mM}(1.03 \mathrm{~g} / \mathrm{L})$ dendroketose with a conversion of $86 \%$, which was calculated with the ratio of dendroketose formation amount to initial concentration of FLAD (Fig. 5b). We also detected a small amount of D-erythrulose $(\sim 0.5 \mathrm{mM})$ which was derived from the aldol reaction between DHAP and FALD. In this multi-enzyme system, the enzyme activity of FLS to FALD was low for DHA production. Combination of mutational hot spots analytical method and site-saturated mutagenesis strategy has increased the catalytic efficiency of FLS to acetaldehyde for $72.9 \%$ [42]. This protein engineering strategy showed the application potential in improving catalytic efficiency of FLS to FALD and further in increasing the production efficiency of dendroketose in the multienzyme system.

\section{Pathway design and strain engineering to produce dendroketose from glycerol}

Glycerol as a major byproduct in biodiesel industry has been considered an abundant and cost-effective feedstock for the production of value-added bioproducts [43-45]. This carbon resource is especially suitable for the production of dendroketose because the conversion of glycerol to DHAP and DHA needs only two enzymatic catalytic reactions which are catalyzed by glycerol dehydrogenase (GDH) and DhaK, respectively (Fig. 6). Here, we investigated the production of dendroketose with glycerol as feedstock through metabolic engineering of C. glutamicum, a Gram-positive soil bacterium generally recognized as safe status. In the previous study, the aldol reaction pathway (pXRTY) based on $\mathrm{RhaD}$ and YqaB [33] and glycerol assimilation pathway (pEFDK) based on GlpF, glycerol dehydrogenase from Klebsiella pneumoniae (DhaD) and DhaK has been combined in widetype strain, resulting in strain WT(pXRTY/pEFDK) [46]. This strain was initially cultured in CGXII minimal salt medium containing $220 \mathrm{mM}$ glycerol and $110 \mathrm{mM}$ DHA. After fermentation for $48 \mathrm{~h}, 5.6 \mathrm{~g} / \mathrm{L}(31.1 \mathrm{mM})$ dendroketose was produced and DHA was absolutely consumed. We still detected $174.5 \mathrm{mM}$ glycerol in the medium. As a result, the dendroketose yield was $0.68 \mathrm{~mol} / \mathrm{mol}$ glycerol. This value was calculated with the ratio of formation of dendroketose to consumption of glycerol (Table 3). When this train was cultured with $220 \mathrm{mM}$ glycerol as sole feedstock, the production decreased sevenfold. This result was probably due to more carbon flux into biomass but less into desired product.

The enzyme triosephosphate isomerase (TPI) catalyzes the isomerization of DHAP to glyceraldehyde 3-phosphate (Ga3P) [47] and then direct carbon flux to biomass. Blockage of this reaction would increase
DHAP accumulation and decrease the biomass formation (Fig. 6). Along this line, we constructed strain SY6(pXRTY/pEFDK) by transferring plasmids pXRTY and pEFDK into strain SY6, in which the gene tpi was eliminated. When this strain was cultivated in CGXII medium with $220 \mathrm{mM}$ glycerol as the sole carbon source, $1.2 \mathrm{~g} / \mathrm{L}(6.7 \mathrm{mM})$ dendroketose was produced. This value was $50 \%$ higher than that of strain WT(pXRTY/pEFDK). However, the production was still far from satisfactory. Second carbon source permitting the generation of ATP and nicotinamide adenine dinucleotide for cell growth should be co-utilized to increase the efficiency of the glycerol assimilation. Accordingly, strain SY6(pXRTY/pEFDK) was cultured in BHI-rich medium containing the same concentration of glycerol. After fermentation for $48 \mathrm{~h}$, this strain produced $6.4 \mathrm{~g} / \mathrm{L}(35.6 \mathrm{mM})$ dendroketose and maintained $141 \mathrm{mM}$ glycerol in the medium (Fig. $7 \mathrm{a}$ and Table 3). The maximum theoretical yield for dendroketose production with glycerol as substrate is 0.5 . In this work, the yield reached $0.45 \mathrm{~mol} / \mathrm{mol}$ glycerol, representing the $90 \%$ of the maximum theoretical value. We also detected small amount of DHA $(4.6 \mathrm{mM})$ in the medium.

\section{Metabolic engineering of dendroketose production from glucose}

Glucose as the most commonly used feedstock can be converted to DHAP via glycolytic pathway in vivo. Enzyme HdpA from C. glutamicum belongs to an HAD super family phosphatase and catalyzes the dephosphorylation of DHAP to DHA [48]. In this case, DHAP and DHA would be obtained from the glucose. In this study, we attempt to synthesize dendroketose with glucose as carbon resource through strain engineering of C. glutamicum (Fig. 6). Firstly, the TPI should be inactivated to efficiently accumulate DHAP in vivo. Secondly, the gene $h d p A$ was overexpressed. Thirdly, the artificial aldol pathway in combination with aldolase RhaD and YqaB from E. coli was introduced to convert the accumulated DHAP and DHA to dendroketose. Accordingly, we constructed an engineered C. glutamicum strain SY6(pXRTYH), wherein the gene tpi was deleted and genes of RhaD, YqaB, and HdpA were overexpressed via plasmid pXRTYH (Table 4). Similarly, strain SY6(pXFucTYH) was constructed via replacement of RhaD with FucA. We have not detected the production of dendroketose in strain WT(pXRTYH) because of scarce accumulation of DHAP in wide-type strain [33]. Fermentation of strain SY6(pXRTYH) gave $36.3 \mathrm{~g} / \mathrm{L}$ of dendroketose with a yield of $0.46 \mathrm{~mol} / \mathrm{mol}$ glucose within $24 \mathrm{~h}$ (Fig. $7 \mathrm{~b}$ and Table 3), whereas strain SY6(pXFucTYH) only produced 


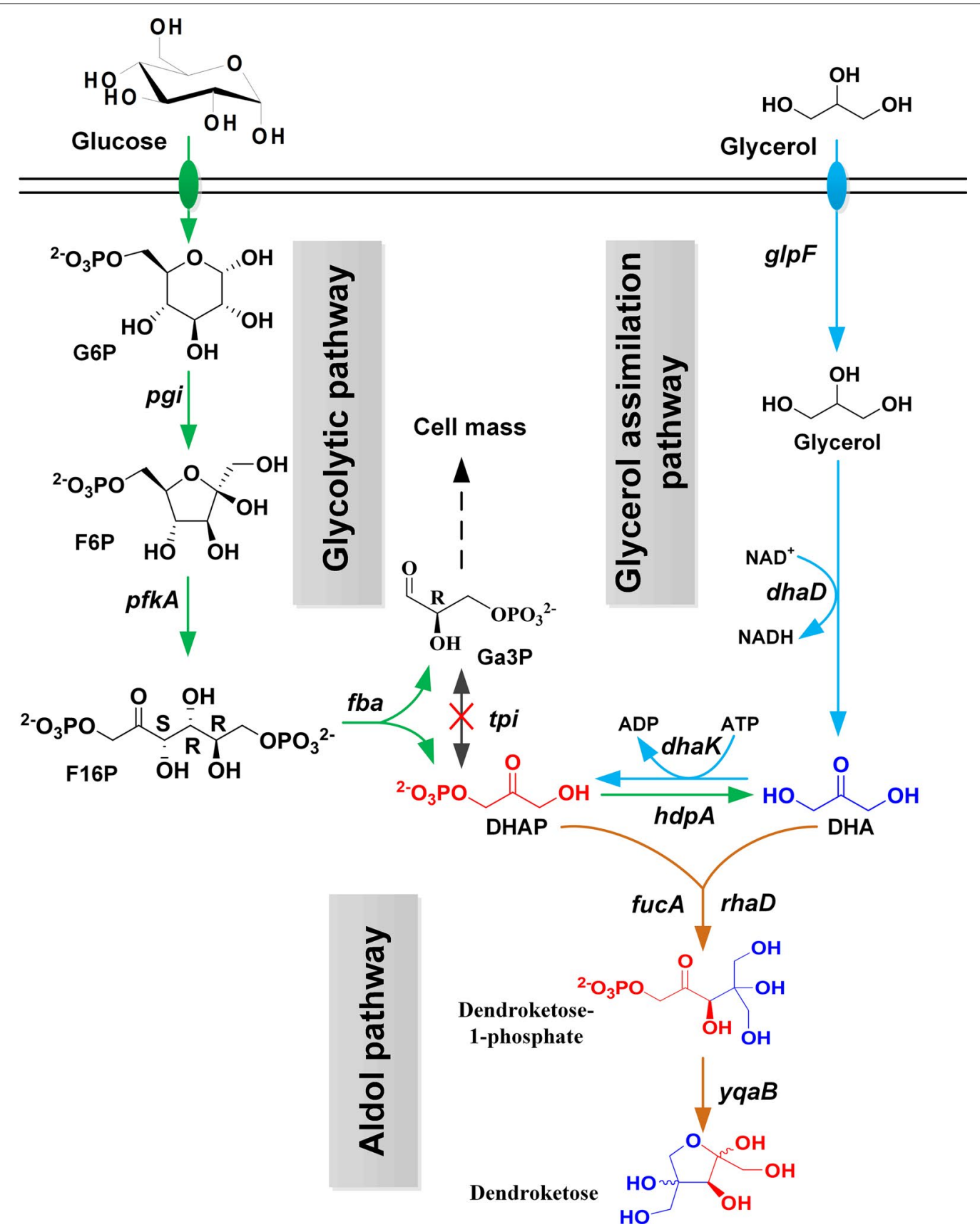

Fig. 6 Pathway design and strain engineering in C. glutamicum to synthesize dendroketose from glycerol and glucose. glpF glycerol facilitator, dhaD glycerol dehydrogenase, dhaK ATP-dependent dihydroxyacetone kinase, G6P glucose 6-phosphate, F6P fructose 6-phosphate, F16P fructose 1,6-phosphate, Ga3P D-glyceraldehyde 3-phosphate, pgi encoding glucose-6-phosphate isomerase, pfkA encoding 6-phosphofructokinase, fba encoding fructose-bisphosphate aldolase, tpi encoding triosephosphate isomerase, $h d p A$ encoding a HAD superfamily phosphatase, rhaD encoding L-rhamnulose-1-phosphate aldolase, fucA encoding L-fuculose-1-phosphate aldolase, yqaB encoding fructose-1-phosphatase

$8.2 \mathrm{~g} / \mathrm{L}$ of dendroketose (Additional file 1: Figure S4). The production would further increase during fermentation optimizations.

\section{Conclusion}

In summary, the detailed catalytic property of RhaD and FucA from E. coli in direct aldol addition using DHA as electrophile acceptor was characterized. The 
Table 3 Synthesis of dendroketose using different carbon sources

\begin{tabular}{|c|c|c|c|c|}
\hline Strains & Medium & Substrates & Production $(\mathrm{g} / \mathrm{L})$ & Yield (mol $/ \mathrm{mol})$ \\
\hline WT(pXRTY/pEFDK) & CGXII & Glycerol and DHA & $5.6 \pm 0.4$ & $0.68 \pm 0.03$ \\
\hline WT(pXRTY/pEFDK) ${ }^{b}$ & CGXII & Glycerol & $0.8 \pm 0.1$ & $0.05 \pm 0.01$ \\
\hline SY6(pXRTY/pEFDK) ${ }^{b}$ & CGXII & Glycerol & $1.2 \pm 0.2$ & $0.46 \pm 0.02$ \\
\hline SY6(pXRTY/pEFDK) $)^{b}$ & $\mathrm{BHI}$ & Glycerol & $6.4 \pm 0.4$ & $0.45 \pm 0.02$ \\
\hline WT(pXRTYH)c & CGXII & Glucose & ND & - \\
\hline SYG $(p X R T Y H)^{c}$ & CGXII & Glucose & $36.3 \pm 1.3$ & $0.46 \pm 0.02$ \\
\hline SY6(pXFucTYH) ${ }^{c}$ & CGXII & Glucose & $8.2 \pm 0.6$ & $0.12 \pm 0.02$ \\
\hline
\end{tabular}

ND not detected

a The initial concentration of glycerol and DHA was $220 \mathrm{mM}$ and $110 \mathrm{mM}$, respectively

b The initial concentration of glycerol was $220 \mathrm{mM}$

c The initial concentration of glucose was $220 \mathrm{mM}$. The fermentation was carried out for $48 \mathrm{~h}$. Mean and standard deviation were calculated based on triplicate experiments
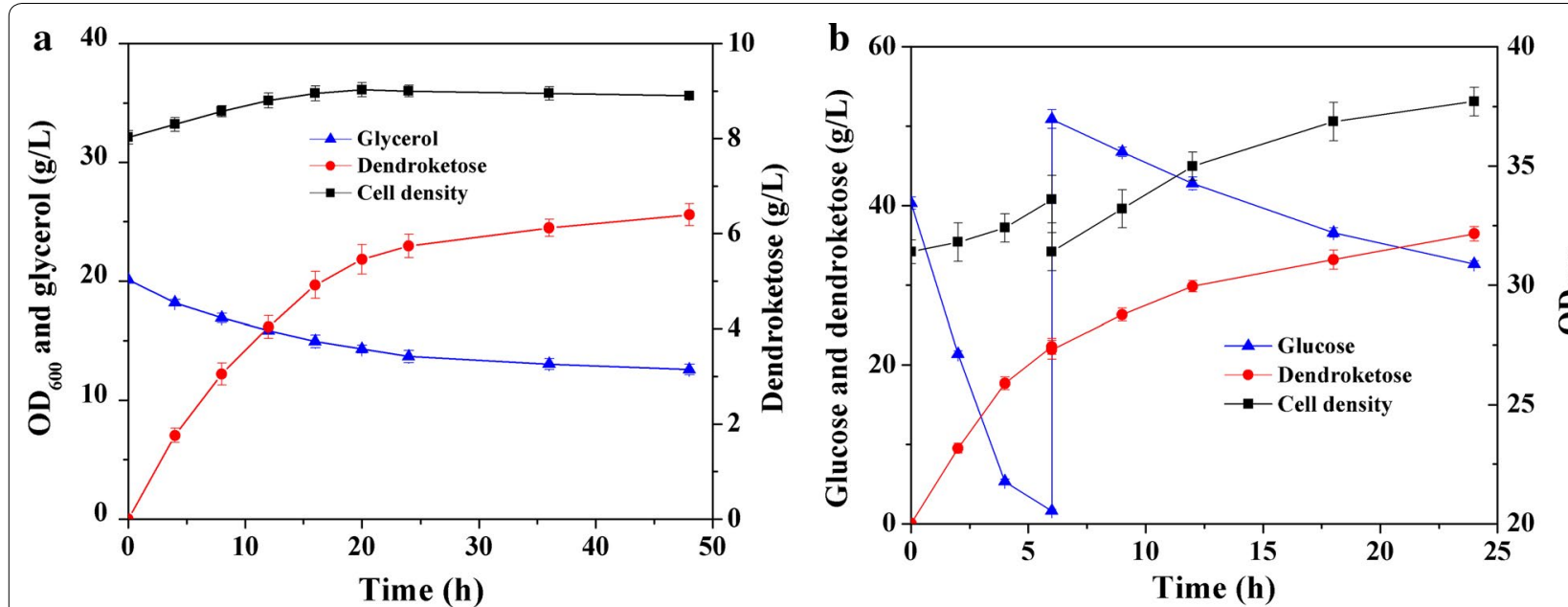

Fig. 7 a Fermentation of strain SY6(pXRTY/pEFDK) to produce dendroketose from glycerol. The strain was cultivated in BHI-rich medium containing $220 \mathrm{mM}$ glycerol. b Fermentation of strain SY6(pXRTYH) to produce dendroketose from glucose. The initial concentration of glucose concentration was $220 \mathrm{mM}$, and additional $220 \mathrm{mM}$ glucose was supplemented into the reaction medium after $6 \mathrm{~h}$ to increase the production. Mean and error bars were calculated based on triplicate experiments

Bürgi-Dunitz trajectory calculated by MD simulations has been applied to reveal the catalytic efficiency difference of those two aldolases. Furthermore, we provided a green and environment-friendly biocatalytic approach to synthesize a rare branched-chain sugar dendroketose directly from FALD with high conversion rate. The synthesis of dendroketose from renewable feedstock glucose or glycerol using an engineered strain was also achieved with high titre and yield. Those advanced routes developed in this study presented low-cost way in producing dendroketose. Chemical dehydration of dendroketose will obtain 4-HMF, which serves as a potential platform molecule in preparing certain biofuels and fine chemicals.

\section{Methods}

Bacterial strains, plasmids and materials

Compounds DHAP, DHA, L-GAL, AP from potato, isopropyl- $\beta$ - $D$-thiogalactopyranoside (IPTG), polyphosphate, ATP, L-fructose, L-tagatose, glycerol, glucose, and antibiotics were purchased from SigmaAldrich. All restriction enzymes and DNA ligase were purchased from Novagen (Darmstadt, Germany). NiNTA affinity chromatography column was purchased from QIAGEN. The yeast extract and tryptone were purchased from OXOID LID, and brain heart infusion (BHI) was purchased from Becton, Dickinson and Company. All bacterial strains and plasmids are listed in Table 4. 
Table 4 Strains and plasmids used in this study

\begin{tabular}{|c|c|c|}
\hline Strains and plasmids & Genotype and properties & Source or references \\
\hline \multicolumn{3}{|l|}{ Strain } \\
\hline E. coli DH5a & 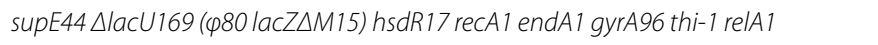 & Novagen \\
\hline E. coli BL21 (DE3) & F-ompT hsdSB (Rb-mB-) gal ( $\lambda$ c I 857 ind1 Sam7 nin5 lacUV5 T7gene1) dcm (DE3) & Novagen \\
\hline C. glutamicum & Wild-type strain & ATCC13032 \\
\hline SY6 & Gene tpi knock-out in C. glutamicum 13032 & [40] \\
\hline WT(pXRTYH) & Wide-type containing plasmid pXRTYH & This study \\
\hline SY6(pXRTYH) & Strain SY6 containing plasmid pXRTYH & This study \\
\hline SY6(pXFucTYH) & Strain SY6 containing plasmid pXFucTYH & This study \\
\hline WT(pXRTY/pEFDK) & Wide-type containing plasmid pXRTY and pEFDK & [46] \\
\hline SY6(pXRTY/pEFDK) & Strain SY6 containing plasmid pXRTY and pEFDK & This study \\
\hline \multicolumn{3}{|l|}{ Plasmid } \\
\hline $\mathrm{pET} 21 \mathrm{a}(+)$ & Expression vector, $A p^{R}$ & Invitrogen \\
\hline pET21-RhaD & pET21a(+) derivative carrying gene of $r$ haD & [40] \\
\hline pET21-FucA & pET21a(+) derivative carrying gene of fucA & This study \\
\hline pET21-FLS & pET21a(+) derivative carrying gene of FLS & [34] \\
\hline pET21-YqaB & pET21a(+) derivative carrying gene of yqaB & [38] \\
\hline pET21-DhaK & pET21a(+) derivative carrying gene of DhaK & This study \\
\hline pXRTY & pXMJ19 derivative carrying gene of $r h a D$ and yqaB & [40] \\
\hline pEFDK & pECXK99E derivative carrying gene of glpF, dhaD and dhaK & {$[46]$} \\
\hline pXRTYH & pXRTY derivative carrying gene of $h d p A$ & This study \\
\hline pXFucTYH & pXFucTY derivative carrying gene of $h d p A$ & This study \\
\hline
\end{tabular}

\section{Vectors and strains construction}

The genes fucA from E. coli and dhaK from Citrobacter freundii were amplified from genome and cloned into pET-21a $(+)$ to obtain pET21-FucA and pET21-DhaK, respectively. The plasmid pET21-PPK containing the gene of ppk from Rhodobacter sphaeroides was kindly provided by Professor Chun You in our institute. For the construction of plasmid pXRTYH and pXFucTYH, gene hdpA was amplified from C. glutamicum 13032 genome. The amplified fragments were ligated into plasmid previous constructed plasmids pXRTY [40] and pXFucTY [46] at the SmaI and SacI sites to obtain pXRTYH and pXFucTYH, respectively. The constructed plasmids were then electroporated into the recombinant strain SY6, in which the gene tpi has been eliminated, to generate strains SY6(pXRTYH) and SY6(pXFucTYH). Plasmid pEFDK containing genes $g l p F$, dhaD and dhaK [46] and pXRTY were co-transformed into SY6 strain to obtain SY6(pXRTY/pEFDK).

\section{Recombinant proteins expression and purification}

Escherichia coli BL21(DE3) strains harboring expression plasmids were cultured at $37{ }^{\circ} \mathrm{C}$ in $1 \mathrm{~L} \mathrm{LB}$ medium containing $100 \mathrm{mg} / \mathrm{L}$ ampicillin to an optical density $\mathrm{OD}_{600}$ of 0.6. 0.5 mM IPTG was added into the culture to induce protein expression and the temperature was adjusted to $16{ }^{\circ} \mathrm{C}$ to avoid inclusion body formation. After incubation for an additional $20 \mathrm{~h}$, cells were harvested, washed twice and suspended in $50 \mathrm{mM}$ triethanolamine (TEA) ( $\mathrm{pH}$ 7.5) buffer. The suspension cells were then lysed by sonication and centrifuged at $14,000 \times g$ and $4{ }^{\circ} \mathrm{C}$ for $10 \mathrm{~min}$. Clear supernatant was collected and loaded onto an $\mathrm{Ni}^{2+}$-NTA-agarose column pre-equilibrated with binding buffer $(50 \mathrm{mM}$ TEA buffer, $300 \mathrm{mM} \mathrm{NaCl}, 20 \mathrm{mM}$ imidazole, $\mathrm{pH}$ 7.5). The retained proteins were recovered with elution buffer (50 mM TEA buffer, $300 \mathrm{mM} \mathrm{NaCl}$, $300 \mathrm{mM}$ imidazole, $\mathrm{pH}$ 7.5). The eluted fraction containing purified protein was dialyzed to eliminate buffer, salt and imidazole. The purified enzymes were freeze dried using a vacuum pump and stored at $-20{ }^{\circ} \mathrm{C}$.

\section{Enzyme activity assay}

The activity of PPK was assayed in a reaction mixture $(200 \mu \mathrm{L})$ containing PPK $(0.05 \mathrm{mg}), 25 \mathrm{mM}$ TEA buffer (pH 7.0), $25 \mathrm{mM}$ DHA, $10 \mathrm{mM}$ ADP, $10 \mathrm{mM}$ polyphosphate and $5 \mathrm{mM} \mathrm{MgCl}_{2} \cdot 6 \mathrm{H}_{2} \mathrm{O}$. After the reaction at $30^{\circ} \mathrm{C}$ for $30 \mathrm{~min}$, the reaction was stopped by the addition of $10 \% \mathrm{H}_{2} \mathrm{SO}_{4}(0.5 \mu \mathrm{L})$. Product was determined via highperformance liquid chromatography (HPLC). One unit of enzyme activity was defined as the enzyme amount catalyzing the consumption of $1 \mu \mathrm{mol}$ DHA per min.

The activity of FLS was assayed in a reaction mixture $(200 \mu \mathrm{L})$ containing FLS $(2 \mathrm{mg}), 25 \mathrm{mM}$ TEA buffer $(\mathrm{pH}$ 7.0), $25 \mathrm{mM}$ FALD, $1 \mathrm{mM} \mathrm{MgSO}_{4}$ and $0.1 \mathrm{mM}$ TPP. 
After the reaction at $30{ }^{\circ} \mathrm{C}$ for $45 \mathrm{~min}$, the reaction was stopped by the addition of $10 \% \mathrm{H}_{2} \mathrm{SO}_{4}(0.5 \mu \mathrm{L})$. One unit of enzyme activity was defined as the enzyme amount catalyzing the formation of $1 \mu \mathrm{mol}$ of total DHA and GA per min.

\section{Steady-state kinetic parameters of RhaD and FucA to DHA and L-GAL}

Reaction: aldol addition of DHAP to L-GAL. To a solution containing freshly neutralized DHAP $(60 \mathrm{mM})$ and RhaD (0.05 mg powder) in $50 \mathrm{mM}$ TEA buffer $\mathrm{pH} 7.5$ at $25{ }^{\circ} \mathrm{C}$, different amounts of L-GAL $(0.2,0.5,2,5,10,20$, $40,60 \mathrm{mM})$ were added. The final volume was $400 \mu \mathrm{L}$. Samples $(40 \mu \mathrm{L})$ were withdrawn at different times $(0,2$, $5,10,20,30 \mathrm{~min}$ ) and the reaction was stopped by the addition of $10 \% \mathrm{H}_{2} \mathrm{SO}_{4}(0.5 \mu \mathrm{L})$. Samples were then analyzed by HPLC to measure the L-GAL consumption. One mmol of L-GAL consumed was equivalent to $1 \mathrm{mmol}$ of L-fructose-1-phosphate formed.

Reaction: aldol addition of DHAP to DHA. To a solution containing freshly neutralized DHAP $(60 \mathrm{mM})$ and RhaD (0.05 mg powder) in $50 \mathrm{mM}$ TEA buffer $\mathrm{pH} 7.5$ at $25^{\circ} \mathrm{C}$, different amounts of DHA $(2,5,10,20,40,60$, $80 \mathrm{mM}$ ) were added. The final volume was $400 \mu \mathrm{L}$. Samples $(40 \mu \mathrm{L})$ were withdrawn at different times $(0,2,5,10$, $20,30 \mathrm{~min}$ ) and the reaction was stopped by the addition of $10 \% \mathrm{H}_{2} \mathrm{SO}_{4}(0.5 \mu \mathrm{L})$. Samples were then analyzed by HPLC to measure the DHA consumption. One mmol of DHA consumed was equivalent to $1 \mathrm{mmol}$ of adduct formed.

Reaction: aldol addition of DHAP to L-GAL. To a solution containing freshly neutralized DHAP $(60 \mathrm{mM})$ and FucA ( $0.1 \mathrm{mg}$ powder) in $50 \mathrm{mM}$ TEA buffer $\mathrm{pH} 7.5$ at $25{ }^{\circ} \mathrm{C}$, different amounts of L-GAL $(0.5,2,5,10,20,40$, $60 \mathrm{mM}$ ) were added. The final volume was $400 \mu \mathrm{L}$. Samples $(40 \mu \mathrm{L})$ were withdrawn at different times $(0,2,5,10$, 20, $30 \mathrm{~min}$ ) and the reaction was stopped by the addition of $10 \% \mathrm{H}_{2} \mathrm{SO}_{4}(0.5 \mu \mathrm{L})$. Samples were then analyzed by HPLC to measure the L-GAL consumption. One millimole of L-GAL consumed was equivalent to $1 \mathrm{mmol}$ of L-tagatose-1-phosphate formed.

Reaction: aldol addition of DHAP to DHA. To a solution containing freshly neutralized DHAP $(60 \mathrm{mM})$ and FucA ( $0.1 \mathrm{mg}$ powder) in $50 \mathrm{mM}$ TEA buffer $\mathrm{pH} 7.5$ at $25^{\circ} \mathrm{C}$, different amounts of DHA $(2,5,10,20,40,60,80$, $100,200 \mathrm{mM}$ ) were added. The final volume was $400 \mu \mathrm{L}$. Samples $(40 \mu \mathrm{L})$ were withdrawn at different times (10, $20,40,60,90,120,180 \mathrm{~min}$ ) and the reaction was stopped by the addition of $10 \% \mathrm{H}_{2} \mathrm{SO}_{4}(0.5 \mu \mathrm{L})$. Samples were then analyzed by HPLC to measure the DHA consumption. One mmol of DHA consumed was equivalent to $1 \mathrm{mmol}$ of adduct formed.

\section{Aldol reactions with DHAP and DHA as substrates}

The reaction mixture $(1 \mathrm{~mL})$ contained freshly neutralized $50 \mathrm{mM}$ DHAP solution, $50 \mathrm{mM}$ DHA, $50 \mathrm{mM}$ TEA buffer (pH 7.5) and RhaD (1 mg) or FucA ( $2 \mathrm{mg})$. The reaction mixture was transferred to a 1.5-mL Eppendorf tube and shaken at $25{ }^{\circ} \mathrm{C}$ and $120 \mathrm{rpm}$ for $24 \mathrm{~h}$. Then, the $\mathrm{pH}$ of the mixture was adjusted to $4.5-5.5$ using $10 \%$ $\mathrm{H}_{2} \mathrm{SO}_{4}$, and $2 \mathrm{U}$ AP was supplemented. The dephosphorylation reaction was performed at $30{ }^{\circ} \mathrm{C}$ for another $24 \mathrm{~h}$.

\section{Molecular modeling}

Models of the dimer structures of FucA complex and RhaD complex were generated as follows: the monomer structure of FucA is derived from the previous study (PDB code 4FUA). However, there is no available polymer structure of FucA by searching the PDB database. TM-align program [49] was used to search for FucA homologies; in the top 10 hits ranked by TM-score, 2OPI crystalized in polymers was used as template. In the case of RhaD, the X-ray structure (PDB code 1GT7) was directly used as the basis for dimer creation of RhaD. The coordinates of the donor DHAP and the acceptor DHA/ L-GAL in constructed dimers were superimposed with those from the PDB codes 1OJR and 4FUA.

Based on the catalytic mechanism of class II Aldolase, a specific residue in the adjacent monomer (Tyr113' in FucA, and Glu171' in RhaD) plays a key role on the protonation of the carbonyl oxygen of ketone acceptors. Therefore, dimer models of enzyme-substrate complexes (dubbed as "FucA-DHAP-DHA", "FucA-DHAP-GAL", "RhaD-DHAP-DHA" and "RhaD-DHAP-GAL") were built to reflect the catalytic mechanism.

During the simulations, a constant force of $10 \mathrm{kcal} / \mathrm{mol}$ between the nucleophile $\mathrm{C}$-atom and the electrophile $\mathrm{C}$-atom was constructed via the consideration of Van der Waals' force. To estimate the stability of 100 ns trajectories of the four systems, root-mean-square deviation (RMSD) for all $C_{\alpha}$ atoms was analyzed and no significant structure difference was observed. Furthermore, rootmean-square fluctuation (RMSF) which could reflect the stability of individual residue of protein was also evaluated; most residues are stable except for the terminations between two monomers.

\section{Molecular dynamics (MD) simulations}

The initial structures used for MD simulation were obtained from modeling analysis. Each apo-protein was protonated at $\mathrm{pH} 7.5$ using $\mathrm{H}++$ webserver. The Amber ff14SB force field was employed for the protein in all the MD simulations [50]. $\mathrm{Na}^{+}$ions were added to neutralize the system, and the TIP3P water model was used to 
solvate each system, ensuring a solvent layer of at least $10 \AA$ from any point on the protein surface. Charges and parameters for ligands were generated with the Antechamber module using the AM1-BCC charge model along with the amber GAFF force field. The force field of zinc ion and its neighboring atoms (cutoff was set as $2.8 \AA$ ) were parameterized using 'MCPB.py' modeling, using a hybrid bonded/restrained nonbonded model. As a result, the three histidine residues (H92, H94 and H155 in FucA, and H141, H143 and H212 in RhaD) were attached to zinc ion by coordinate bonds, whereas the two oxygen atoms of donor were attached to zinc ion by applying harmonic restraint $(100 \mathrm{kcal} / \mathrm{mol})$. After proper parameterizations and setup, the resulting system's geometries were minimized (5000 steps for steepest conjugate and 5000 steps for conjugate gradient) to remove poor contacts and relax the system. The systems were then annealed from 0 to $300 \mathrm{~K}\left(\approx 27^{\circ} \mathrm{C}\right)$ to mimic experimental temperature under the constant amount of substance $(N)$, volume $(V)$ and temperature (T) (NVT ensemble) for $50 \mathrm{ps}$. Subsequently, the systems were maintained for 25 ps of density equilibration under constant amount of substance $(N)$, pressure $(P)$ and temperature $(T)$ (NPT ensemble) at constant temperature of $300 \mathrm{~K}$ and pressure of $1.0 \mathrm{~atm}$ using Langevin-thermostat $(\mathrm{ntt}=3)$ with collision frequency of $2 \mathrm{ps}^{-1}$ and pressure relaxation time of 1 ps. The heating and density equilibrations were carried out with a weak restraint of $20 \mathrm{kcal} \mathrm{mol}^{-1} \AA^{-2}$ performed on all the residues. The systems were further equilibrated for 250 ps to get well settled pressure and temperature for conformational and chemical analyses. After proper minimizations and equilibrations, a productive MD run of 100 ns was performed for each system. During all MD simulations, the covalent bonds containing hydrogen were constrained using SHAKE algorithm [51], with a MD time step of 2 fs. The trajectory file was written every 1000 steps. All the above MD simulations were performed with GPU version of Amber 16 package. The generated trajectories (interval $=200$, a total of 500 frames for each case) were used for the relative binding energy evaluation.

\section{In vitro cascade reaction}

To synthesize dendroketose in vitro, the reaction mixture $(2 \mathrm{~mL})$ containing $50 \mathrm{mM}$ TEA $(\mathrm{pH} 7.5), 40 \mathrm{mM}$ FALD, $0.1 \mathrm{mM}$ TPP, FLS (1.5 U, $16 \mathrm{mg}$ ) was initially carried out at $25^{\circ} \mathrm{C}$ and $120 \mathrm{rpm}$ for $16 \mathrm{~h}$. Then, DhaK $(0.5 \mathrm{U}$, $0.025 \mathrm{mg}$ ), PPK (0.5 U, $0.03 \mathrm{mg}$ ), RhaD (0.5 U, $2 \mathrm{mg}$ ), YqaB (0.9 U, $1.5 \mathrm{mg})$, polyphosphate $(20 \mathrm{mM})$, ATP $(0.5 \mathrm{mM})$, and $\mathrm{MgSO}_{4}(10 \mathrm{mM})$ were added into the reaction system, and it performed for another $24 \mathrm{~h}$. Samples $(100 \mu \mathrm{L})$ were captured very two hours, treated with $10 \% \mathrm{H}_{2} \mathrm{SO}_{4}$, centrifuged (22,000 rpm, $20 \mathrm{~min})$ and analyzed by HPLC.

\section{Shake flask scale cultivation}

For precultivation of recombinant strain, a single clone was grown in $5 \mathrm{~mL}$ of BHI medium. After incubation for approximately $15 \mathrm{~h}$, cells were inoculated into a $500-\mathrm{mL}$ shake flask containing $100 \mathrm{~mL}$ BHI medium and cultivated at $25^{\circ} \mathrm{C}$ in a rotatory shaker at $220 \mathrm{rpm}$. When the cell $\mathrm{OD}_{600}$ reached $0.8,1 \mathrm{mM}$ IPTG was added to induce enzyme expression. Subsequently, the cells were harvested by centrifugation $\left(8000 \times g, 10 \mathrm{~min}, 4{ }^{\circ} \mathrm{C}\right)$ and were suspended in CGXII medium [52]. Then, $50 \mathrm{~mL}$ cells were transferred into a $250-\mathrm{mL}$ shake flask with an initial $\mathrm{OD}_{600}$ of approximately 30 . When appropriate, $10 \mathrm{mg} / \mathrm{L}$ chloramphenicol and $25 \mathrm{mg} / \mathrm{L}$ kanamycin were added. The fermentation process was carried out at $30^{\circ} \mathrm{C}$ and $200 \mathrm{rmp}$.

If glycerol and DHA were used as substrates, the concentration of glycerol and DHA was assigned to $220 \mathrm{mM}$ and $110 \mathrm{mM}$, respectively. To produce dendroketose from glucose, $220 \mathrm{mM}$ glucose was supplemented into the medium. For the fed-batch fermentation, $220 \mathrm{mM}$ glucose was supplemented again into the medium after fermentation for $6 \mathrm{~h}$. Samples were collected every $2 \mathrm{~h}$ and centrifuged at $14,000 \times g$ for $20 \mathrm{~min}$. The resulting supernatants were analyzed by HPLC. The desired product was separated by a chromatographic column filled with $\mathrm{Ca}^{2+}$ ion exchange resin, identified by a refractive index detector and then collected by a fraction collector. The purified products were analyzed by NMR.

\section{Analytical methods}

Cell density was determined by measuring the optical density at $600 \mathrm{~nm}\left(\mathrm{OD}_{600}\right)$ with a UV-Vis spectrophotometer (TU-1901, Persee, Beijing, China). Cell dry weight $(\mathrm{CDW}, \mathrm{g} / \mathrm{L})$ of $E$. coli was calculated from $\mathrm{OD}_{600}$ values using the experimentally determined correlation factor of $0.25 \mathrm{~g}$ cells (dry weight [DW])/liter for an $\mathrm{OD}_{600}$ of 1 . Protein concentrations were determined by the Bradford method using bovine serum albumin as a standard. HPLC system (Agilent 1100 series, HewlettPackard) equipped with a refractive index detector and fitted with chromatographic column (Bio-Rad Aminex HPX-87H column or Waters Sugar-Pak I column) was used to qualitative and quantitative analysis of substrates and products.

\section{Additional file}

Additional file 1: Figure S1. Root mean square deviations (RMSD) measured during $100 \mathrm{~ns}$ MD simulation. Figure S2. Root mean squared fluctuations (RMSF) measured during $100 \mathrm{~ns}$ MD simulation. The terminations 
between two monomers are highlighted with yellow box. The monomer size of FucA is 206 aa, whilst 274 aa for RhaD monomer. Figure S3. The standard curve of verified dendroketose. Figure $\mathbf{S 4}$. Fermentation of strains SY6(pXFucTYH) to produce dendroketose from low cost glucose. The initial glucose concentration was $220 \mathrm{mM}$, and glucose was additional supplemented into the reaction medium at the reaction time for $6 \mathrm{~h}$ to increase dendroketose production. Figure $\mathbf{S 5}$. MS data of dendroketose synthesized by RhaD and AP. Figure S6. MS data of dendroketose synthesized by FucA and AP. Figure S7. Observed NMR spectra of dendroketose obtained by RhaD. Figure S8. Observed NMR spectra of dendroketose obtained by FucA.

\section{Authors' contributions}

$J Y$ and $Y Z$ contributed equally to this work. They performed the experiments including enzyme screening, characterization and strain construction and drafted the manuscript. GQ performed the in silico simulations via molecular dynamics (MD). YZ, CT and CD carried out the experiments including product purification, MS and NMR analysis. YM and LD finished the fermentation experiments. ZS, YS and YM designed the constructs and revised the manuscript. All authors reviewed the results of the manuscript. All authors read and approved the final manuscript.

\section{Author details}

${ }^{1}$ National Engineering Laboratory for Industrial Enzymes, Tianjin Institute of Industrial Biotechnology, Chinese Academy of Sciences, Tianjin 300308, China. ${ }^{2}$ School of Pharmacy, Tianjin Medical University, Tianjin, China.

\section{Acknowledgements}

Not applicable.

\section{Competing interests}

The authors declare that they have no competing interests.

\section{Availability of data and materials}

The dataset supporting the conclusions of this article is included within the article (and its Additional file).

\section{Consent for publication}

Not applicable.

\section{Ethics approval and consent to participate} Not applicable.

\section{Funding}

This work was supported by the Natural Science Foundation of China (No. 21602245), Key Programs of the Chinese Academy of Sciences (No. ZDRWZS-2016-3), Youth Innovation Promotion Association of Chinese Academy of Sciences. Zhoutong Sun also thanks to the CAS Pioneer Hundred Talent Program (Type C) (reference number 2016-053) for initial start support.

\section{Publisher's Note}

Springer Nature remains neutral with regard to jurisdictional claims in published maps and institutional affiliations.

Received: 19 June 2018 Accepted: 15 October 2018 Published online: 25 October 2018

\section{References}

1. Fessner WD. Modern aldol reactions. Weinheim: Wiley; 2004.

2. Machajewski TD, Wong $\mathrm{CH}$. The catalytic asymmetric aldol reaction. Angew Chem Int Ed. 2000;39:1352-74

3. Shibasaki M, Kanai M. Asymmetric synthesis of tertiary alcohols and a-tertiary amines via Cu-catalyzed C-C bond formation to ketones and ketimines. Chem Rev. 2008;108:2853-73.
4. Lam HW, Joensuu PM. Cu(I)-catalyzed reductive aldol cyclizations: diastereo- and enantioselective synthesis of $\beta$-hydroxylactones. Org Lett. 2005;7:4225-8

5. Oisaki K, Suto Y, Kanai M, Shibasaki M. A new method for the catalytic aldol reaction to ketones. J Am Chem Soc. 2003;125:5644-5.

6. Deschamp J, Chuzel O, Hannedouche J, Riant O. Highly diastereo- and enantioselective copper-catalyzed domino reduction/aldol reaction of ketones with methyl acrylate. Angew Chem Int Ed. 2006;45:1292.

7. Dean SM, Greenberg WA, Wong CH. Recent advances in aldolase-catalyzed asymmetric synthesis. Adv Synth Catal. 2007;349:1308-20.

8. Schmidt NG, Eger E, Kroutil W. Building bridges biocatalytic C $-\mathrm{C}$ bond formation toward multifunctional products. ACS Catal. 2016;6:4286-311.

9. Brovetto M, Gamenara D, Méndez PS, Seoane GA. C-C bond-forming lyases in organic synthesis. Chem Rev. 2011;111:4346-403.

10. Clapés P, Garrabou X. Current trends in asymmetric synthesis with aldolases. Adv Synth Catal. 2011;13:2263-83.

11. Sugiyama M, Watanabe K, Funakoshi N, Amino Y, Ka-wahara S, Takemoto T. Process for production of glutamic acid derivatives. 2002JP12852, 2003056026, WO2003/056026. Ajinomoto Co., Inc.

12. Laurent $V$, Darii E, Aujon A, Debacker M, Petit JL, Hélaine V, Liptaj T, Breza M, Mariage A, Nauton L, Traïkia M, Salanoubat M, Lemaire M, GuérardHélaine C, de Berardinis V. Synthesis of branched-chain sugars with a DHAP-aldolase: ketones are electrophile substrates of rhamnulose1-phosphate aldolases. Angew Chem Int Ed. 2018;130:5565-9.

13. Granstrom TB, Takata G, Tokuda M, Izumori K. Izumoring: a novel and complete strategy for bioproduction of rare sugars. J Biosci Bioeng. 2004;97:89-94.

14. Schaffer R. Synthesis of higher ketoses by aldol reactions. II. unsubstituted heptuloses. J Org Chem. 1963;28:1929.

15. Enders D, Grondal C. Direct organocatalytic de novo synthesis of carbohydrates. Angew Chem Int Ed. 2005:44:1210-2.

16. Cui M, Deng J, Li X, Fu Y. Production of 4-hydroxymethylfurfural from derivatives of biomass-derived glycerol for chemicals and polymers. Sustain Chem Eng. 2016;4(3):1707-14.

17. Wang GH, Hilgert J, Richter FH, Wang F, Bongard HJ, Spliethoff B, Weidenthaler C, Schuth F. Platinum-cobalt bimetallic nanoparticles in hollow carbon nanospheres for hydrogenolysis of 5-hydroxymethylfurfural. Nat Mater. 2014;13:293-300.

18. Thananatthanachon T, Rauchfuss TB. Efficient production of the liquid fuel 2,5-dimethylfuran from fructose using formic acid as a reagent. Angew Chem. 2010;122:6766-8.

19. Deng J, Pan T, Xu Q, Chen MY, Zhang Y, Guo QX, Fu Y. Linked strategy for the production of fuels via formose reaction. Sci Rep. 2013;3:1244.

20. Samland AK, Sprenger GA. Microbial aldolases as C-C bonding enzymesunknown treasures and new developments. Appl Microbiol Biotechnol. 2006;71:253.

21. Jung $\mathrm{SH}$, Jeong JH, Miller $\mathrm{P}$, Wong $\mathrm{CH}$. An efficient multigram-scale preparation of dihydroxyacetone phosphate. J Org Chem. 1994;59:7182-4.

22. Li A, Cai L, Chen Z, Wang M, Wang N, Nakanishi H, Gao XD, Li Z. Recent advances in the synthesis of rare sugars using DHAP-dependent aldolases. Carbohydr Res. 2017;452:108-15.

23. Busto E. Recent developments in the preparation of carbohydrate derivatives from achiral building blocks by using aldolases. ChemCatChem. 2016;8:2589-98.

24. Falcicchio P, Wolterink-Van Loo S, Franssen MC, van der Oost J. DHAPdependent aldolases from (hyper) thermophiles: biochemistry and applications. Extremophiles. 2014;18:1-13.

25. Garrabou X, Joglar J, Parella T, Crehuet R, Bujons J, Clapés P. Redesign of the phosphate binding site of L-rhamnulose-1-phosphate aldolase towards a dihydroxyacetone dependent dldolase. Adv Synth Catal. 2011;353:89-99.

26. Kroemer M, Merkel I, Schulz GE. Structure and catalytic mechanism of L-rhamnulose-1-phosphate aldolase. Biochemistry. 2003;42:10560-8.

27. Dreyer MK, Schulz GE. Catalytic mechanism of the metal-dependent fuculose aldolase from Escherichia coli as derived from the structure. J Mol Biol. 1996;259:458-66.

28. Bürgi HB, Dunitz JD, Shefter E. Geometrical reaction coordinates. II. Nucleophilic addition to a carbonyl group. J Am Chem Soc. 1973;95:5065-7.

29. Bürgi HB, Lehn JM, Wipff $G$. Ab initio study of nucleophilic addition to a carbonyl group. J Am Chem Soc. 1974;96:1956-7. 
30. Light SH, Minasov G, Duban ME, Anderson WF. Adherence to Bürgi-Dunitz stereochemical principles requires significant structural rearrangements in Schiff-base formation: insights from transaldolase complexes. Acta Crystallogr Sect D. 2014;70:544-52.

31. Radisky ES, Koshland DE. A clogged gutter mechanism for protease inhibitors. Proc Natl Acad Sci USA. 2002;99:10316-21.

32. Younes S, Ni Y, Schmidt S, Kroutil W, Hollmann F. Alcohol dehydrogenases catalyze the reduction of thioesters. ChemCatChem. 2017;9:1389-92.

33. Molitor B, Richter $\mathrm{H}$, Martin ME, Jensen RO, Juminaga A, Mihalcea C, Angenent LT. Carbon recovery by fermentation of CO-rich off gasesturning steel mills into biorefineries. Bioresour Technol. 2016;215:386-96.

34. Yang J, Sun S, Men Y, Zeng Y, Zhu Y, Sun Y, Ma Y. Transformation of formaldehyde into functional sugars via multi-enzyme stepwise cascade catalysis. Catal Sci Technol. 2017;7:3459-63.

35. Szekrenyi A, Garrabou X, Parella T, Joglar J, Bujons J, Clapés P. Asymmetric assembly of aldose carbohydrates from formaldehyde and glycolaldehyde by tandem biocatalytic aldol reactions. Nat Chem. 2015;7:724-9.

36. Siegel JB, Smith AL, Poust S, Wargacki AJ, Bar-Even A, Louw C, Shen BW, Eiben CB, Tran HM, Noor E, Gallaher JL, Bale J, Yoshikuni Y, Gelb MH, Keasling JD, Stoddard BL, Lidstrom ME, Baker D. Computational protein design enables a novel one-carbon assimilation pathway. Proc Natl Acad Sci USA. 2015;112:3704-9.

37. Sánchez-Moreno I, García-García JF, Bastida A, García-Junceda E. Multienzyme system for dihydroxyacetone phosphate-dependent aldolase catalyzed C-C bond formation from dihydroxyacetone. Chem Commun. 2004;1:1634-5. https://doi.org/10.1039/B405220J.

38. Yang J, Li J, Men Y, Zhu Y, Zhang Y, Sun Y, Ma Y. Biosynthesis of I-sorbose and I-psicose based on C-C bond formation catalyzed by aldolases in an engineered Corynebacterium glutamicum strain. Appl Environ Microbiol. 2015;81:4284-94.

39. Liu S, LiY, Zhu J. Enzymatic production of I-theanine by Y-glutamylmethylamide synthetase coupling with an ATP regeneration system based on polyphosphate kinase. Process Biochem. 2016;51:1458-63.

40. Yang J, Zhu Y, Li J, Men Y, Sun Y, Ma Y. Biosynthesis of rare ketoses through constructing a recombination pathway in an engineered Corynebacterium glutamicum. Biotechnol Bioeng. 2015;112:168-80.
41. Poust S, Piety J, Bar-Even A, Louw C, Baker D, Keasling JD, Siegel JB. Mechanistic analysis of an engineered enzyme that catalyzes the formose reaction. ChemBioChem. 2015;16:1950.

42. Zhang L, Singh R, Sivakumar D, Guo Z, Li J, Chen F, He Y, Guan X, Kang YC, Lee J-K. An artificial synthetic pathway for acetoin, 2,3-butanediol, and 2-butanol production from ethanol using cell free multi-enzyme catalysis. Green Chem. 2018;20:230-42.

43. Liu D, Chen Z. Toward glycerol biorefinery: metabolic engineering for the production of biofuels and chemicals from glycerol. Biotechnol Biofuel. 2016;9:205.

44. Mazumdar S, Blankschien MD, Clomburg JM, Gonzalez R. Efficient synthesis of L-lactic acid from glycerol by metabolically engineered Escherichia coli. Microb Cell Fact. 2013;12:7.

45. Saini M, Wang ZW, Chiang CJ, Chao YP. Metabolic engineering of Escherichia coli for production of $n$-butanol from crude glycerol. Biotechnol Biofuel. 2017;10:173.

46. Yang J, Zhu Y, Men Y, Sun S, Zeng Y, Zhang Y, Sun Y, Ma Y. Pathway construction in Corynebacterium glutamicum and strain engineering to produce rare sugars from glycerol. J Agric Food Chem. 2016;64:9497-505.

47. Cintolesi A, Clomburg JM, Rigou V, Zygourakis K, Gonzalez R. Quantitative analysis of the fermentative metabolism of glycerol in Escherichia coli. Biotechnol Bioeng. 2012;109:187-98.

48. Jojima T, Igari T, Gunji W, Suda M, Inui M, Yukawa H. Identification of a HAD superfamily phosphatase, HdpA, Involved in 1,3-dihydroxyacetone production during sugar Ca-tabolism in Corynebacterium glutamicum. FEBS Lett. 2012;586:4228-32.

49. Zhang Y, Skolnick J. TM-align: a protein structure alignment algorithm based on the TM-score. Nucleic Acids Res. 2005;33:2302-9.

50. Maier JA, Martinez C, Kasavajhala K, Wickstrom L, Hauser KE, Simmerling C. ff14SB: improving the accuracy of protein side chain and backbone parameters from ff99SB. J Chem Theory Comput. 2015;11:3696-713.

51. Ryckaert JP, Ciccotti G, Berendsen HJC. Numerical integration of the cartesian equations of motion of a system with constraints: molecular dynamics of $n$-alkanes. J Comput Phys. 1977;23:327-41.

52. Eggeling L, Bott M. Handbook of Corynebacterium glutamicum. Boca Raton: CRC; 2005. p. 535-68.
Ready to submit your research? Choose BMC and benefit from:

- fast, convenient online submission

- thorough peer review by experienced researchers in your field

- rapid publication on acceptance

- support for research data, including large and complex data types

- gold Open Access which fosters wider collaboration and increased citations

- maximum visibility for your research: over $100 \mathrm{M}$ website views per year

At BMC, research is always in progress.

Learn more biomedcentral.com/submissions 